Check for updates

Cite this: RSC Adv., 2017, 7, 29899

\title{
A novel method for the clean synthesis of nano- sized cobalt based blue pigments
}

\begin{abstract}
K. Mokhtari and Sh. Salem iD *
Cobalt based pigments are categorized as hazardous materials because they contain a high level of environmentally toxic metals. Therefore, the aim of the present investigation is to partially replace cobalt by magnesium and zinc. The powder compositions are prepared according to the statistical mixture design methodology and $\mathrm{CO}_{1-(x+y)} \mathrm{Mg}_{x} \mathrm{Zn}_{y} \mathrm{Al}_{2} \mathrm{O}_{4}$ is synthesized via sol-gel self-combustion in which glycine is employed as the fuel because it produces nontoxic gases. This study considers a wide range of synthetic factors, including composition $(x+y \leq 0.50)$, calcination temperature $\left(900-1000{ }^{\circ} \mathrm{C}\right)$ and $\mathrm{pH}(2.5-10.5)$. The products are characterized via Fourier transform infrared spectroscopy, X-ray diffraction, Brunauer-EmmettTeller surface area measurement, and scanning and transmission electron microscopy. The $\mathrm{CO}_{0.75} \mathrm{Zn}_{0.25} \mathrm{Al}_{2} \mathrm{O}_{4}$ and $\mathrm{Co}_{0.67} \mathrm{Mg}_{0.16} \mathrm{Zn}_{0.16} \mathrm{Al}_{2} \mathrm{O}_{4}$ pigments have a bright blue color and are approximately identical to the reference composition $\left(\mathrm{CoAl}_{2} \mathrm{O}_{4}\right)$ when synthesized under the neutral conditions. The colorimetric data indicated the formation of blue pigment, corresponding to highly negative $b^{*}$ value, $\sim-30$, for the $\mathrm{Co}_{0.67} \mathrm{Mg}_{0.16} \mathrm{Zn}_{0.16} \mathrm{Al}_{2} \mathrm{O}_{4}$ composition prepared in the acidic condition. A safe and reliable synthetic method was introduced for the synthesis of nano-sized spinel $\leq 30 \mathrm{~nm}$ by the substitution of magnesium and zinc for cobalt in the structure of the pigment. In comparison to cobalt aluminate oxide, the modified composition, which contains 33.33 mol\% magnesium and zinc, can effectively improve chromatic performance, reduce environmental risk and be employed for the economic production of nano-sized pigments.
\end{abstract}

Received 1st April 2017

Accepted 18th May 2017

DOI: 10.1039/c7ra03771f

rsc.li/rsc-advances

\section{Introduction}

The consumption of inorganic pigments has rapidly increased since the early 90 's because of their application in glass and ceramic decorations using ink-jet technology. Cobalt is a chromatic element which is applied to produce a distinct blue color. ${ }^{1}$ In the last decade, the most important challenge faced by pigment producers has been the significant changes in health and environmental regulations, in which cobalt compositions such as $\mathrm{Co}_{3} \mathrm{O}_{4}$ and $\mathrm{CoAl}_{2} \mathrm{O}_{4}$ are classified as hazardous materials. Industrial plants may discharge cobalt into water and soil resulting in dangerous effects on human health and environmental toxicity. In order to reduce the pollution caused by cobalt based pigments, it is necessary to decrease the content of cobalt in pigment compositions using applicable techniques.

The inorganic blue pigment that consists mainly of cobalt and aluminium is an intense chromatic material., ${ }^{2,3}$ The theoretical formula for this spinel is $\mathrm{CoAl}_{2} \mathrm{O}_{4}$ in which the ions are arranged in a cubic close-packed lattice. ${ }^{4}$ There are normal and inverse structures for cobalt aluminate oxide. The normal spinel of $\mathrm{CoAl}_{2} \mathrm{O}_{4}$ displays a blue colour, whereas green powder is characterized by an inverse spinel structure. ${ }^{5}$ Various chemical techniques, such as solid-state reaction, ${ }^{6}$ freeze-drying, ${ }^{7}$ sono-

Faculty of Chemical Engineering, Urmia University of Technology, Urmia, Iran. E-mail: s.salem@che.uut.ac.ir chemical reaction, ${ }^{8}$ co-precipitation, ${ }^{9}$ sol-gel, ${ }^{10}$ emulsion precipitation $^{11}$ and hydrothermal methods, ${ }^{12}$ have been employed to synthesize ultrafine cobalt based pigments. However, these techniques are not only quite complex but also involve long processing times. On the other hand, the sol-gel autoignition technique is well known as a simple, fast and economically viable method to prepare pure nano-structured powders. Sol-gel autoignition typically involves a reaction in a solution of metal nitrates and fuels..$^{1,3,5}$ The success of the process is related to the appropriate selection of fuel or complexing agent and exothermic redox reaction between the fuel and oxidizer. The main factors affecting this reaction include: type of fuel, fuel to oxidizer ratio, mixture of fuels, $\mathrm{pH}$ of solution and rheology of the sol. ${ }^{13,14}$ It seems that the application of fuels containing amino groups can result in the successful preparation of nano-structured $\mathrm{CoAl}_{2} \mathrm{O}_{4}$ via the autoignition synthesis route. ${ }^{15}$ According the investigation performed by Merino et al., ${ }^{16}$ aspartic acid or lysine can be employed as fuels, where the lower crystallite size corresponds to the powder synthesized with aspartic acid.

In order to decrease the cobalt content in blue pigments, modified spinel compositions have been prepared by researchers. A bright blue color was developed by Koroleva ${ }^{17}$ based on the $\mathrm{Co}_{1-x} \mathrm{Mg}_{x} \mathrm{Al}_{2} \mathrm{O}_{4}$ spinel, where $0.67 \leq x \leq 0.80$. Khattab et al..$^{18}$ optimized the calcination temperature for the formation of $\mathrm{Co}_{x} \mathrm{Mg}_{1-x} \mathrm{Al}_{2} \mathrm{O}_{4}$ nano-spinel after microwave 
treatment. Oxalyldihydrazide was used as a fuel by Bao et al. ${ }^{19}$ to prepare new nano-sized blue pigments with the formula $\mathrm{MgAl}_{2} \mathrm{O}_{4}: x \mathrm{Co}^{2+}(0.00 \leq x \leq 0.10)$. It was shown that the substitution of $\mathrm{Fe}^{3+}$ in the $\mathrm{Co}_{0.5} \mathrm{Mg}_{0.5} \mathrm{Al}_{2-x} \mathrm{Fe}_{x} \mathrm{O}_{4}$ structure changes its colour from blue to black. Ianos et $a .^{20}$ used mixtures of urea and $\beta$-alanine as fuels for the preparation of $\mathrm{Mg}_{1-x} \mathrm{Co}_{x} \mathrm{Al}_{2} \mathrm{O}_{4}(x=0.1-0.3)$ powders. New nano-blue ceramic pigments with the formula $\mathrm{Co}_{x} \mathrm{Mg}_{1-x} \mathrm{Al}_{2} \mathrm{O}_{4}(0 \leq x \leq 0.1)$ were prepared via a coprecipitation-combustion hybrid method using urea as a fuel in air atmosphere. ${ }^{21}$ The $\mathrm{Co}_{x} \mathrm{Zn}_{1-x} \mathrm{Al}_{2} \mathrm{O}_{4}$ system was synthesized using a polymeric precursor with the aim to achieve blue pigments. ${ }^{22}$ According to the results reported by Sedghi et $a .^{23}$ the best blue colour is related to $\mathrm{Co}_{0.5} \mathrm{Zn}_{0.5} \mathrm{Al}_{2} \mathrm{O}_{4}$ powder. Visinescu et al. ${ }^{\mathbf{2 4}}$ used starch as a chelating, template and gelation agent for the synthesis of nano-sized $\mathrm{Co}_{x} \mathrm{Zn}_{1-x} \mathrm{Al}_{2} \mathrm{O}_{4}(x=0.0-1.0)$ blue pigments.

The major challenge for the reduced risk, clean and safe commercial manufacture of cobalt based pigments is the indepth understanding of the role of divalent metals due to complex relationship between the nano-crystallite structure and chromatic performance. Although extended investigations regarding the synthesis of cobalt based pigments have been carried out, this study offers a reliable procedure for the development of a blue pigment composition containing magnesium and zinc with a decreased cobalt content. The relationships between the processing parameters are complicated and analysis of the system is tedious work. A systematic investigation using a statistical design of experiments approach is lacking in the literature related to the self-combustion synthesis of cobalt based pigments. Therefore, the mixture design methodology is proposed to determine the optimum composition.

\section{Experimental}

\section{Materials and blend of chemical reagents}

Solutions were prepared using $\mathrm{Al}\left(\mathrm{NO}_{3}\right)_{3} \cdot 9 \mathrm{H}_{2} \mathrm{O}, \mathrm{Co}\left(\mathrm{NO}_{3}\right)_{2} \cdot 6 \mathrm{H}_{2} \mathrm{O}$, $\mathrm{Mg}\left(\mathrm{NO}_{3}\right)_{2} \cdot 6 \mathrm{H}_{2} \mathrm{O} \mathrm{Zn}\left(\mathrm{NO}_{3}\right)_{2} \cdot 6 \mathrm{H}_{2} \mathrm{O}$ which were purchased from Merck Company. Also glycine, $\mathrm{NH}_{2} \mathrm{CH}_{2} \mathrm{COOH}$, (Merck, 56406) was employed as fuel. This fuel can be economically applied for the production of nano-sized spinel which is not only costeffective, but it also reduces the environmental risk due to the generation of nontoxic gases. The main aim of the mixture design methodology is the reliable prediction of dependency between composition and crystallite size and chromatic performance as outcomes of the process with the minimal number of experiments. In this method, the effects of pure, binary and ternary mixtures of starting materials are evaluated on chromatic performance as well as crystallite size. The binary and ternary mixing of nitrates provides the second and third order interactions of metals. Fig. 1 shows the location of points in the mixture space and the metal fractions are given in Table 1. In order to evaluate the physico-chemical characteristics of $\mathrm{CoAl}_{2} \mathrm{O}_{4}$, only the point at the vertex of triangle, A, was considered. In the other vertices, the proportions of magnesium and zinc are considered to be 0.50 ; therefore, the cobalt proportion varies between 0.50 and 1.00. The internal points between the centroid and vertices represent the axial

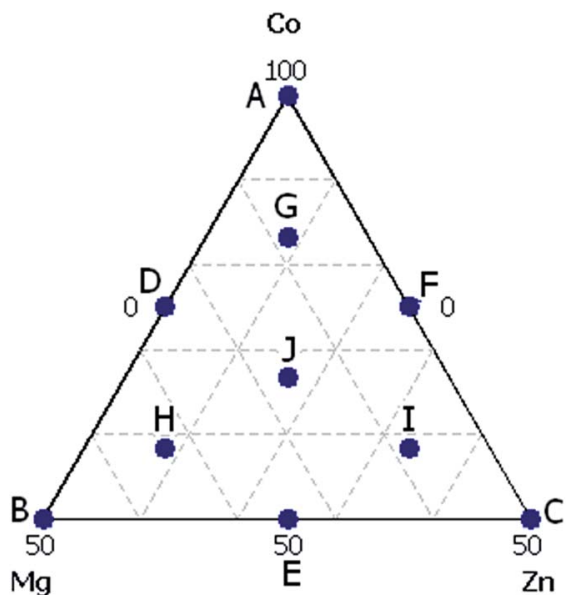

Fig. 1 Proportions of metals for preparation of blue pigment spinel according to the mixture design methodology with a metal mole/Al ratio of 0.50 .

compositions which contain a $2 / 3$ portion of one vertex and $1 / 6$ portions of other components. In this experimental design technique, the total moles of divalent metals are kept constant and measured characteristics can be evaluated as a function of metal proportions. In a system with $n$ materials, there are $n-1$ independent compositions. A generalized polynomial equation for a system with three divalent metals, $f\left(x_{1}, x_{2}, x_{3}\right)$, which describes the measured characteristic, can be adjusted as: ${ }^{25}$

$$
\begin{aligned}
f\left(x_{1}, x_{2}, x_{3}\right)= & \beta_{0}+\sum \beta_{i} x_{i}+\sum \sum_{i<j} \beta_{i j} x_{i} x_{j} \\
& +\sum \sum_{i<j} \sum_{j<k} \beta_{i j k} x_{i}^{2} x_{j} x_{k}+\ldots
\end{aligned}
$$

where, $x$ is the molar proportion of metal and $\beta$ is the coefficient of the adjusted equation. This polynomial should be evaluated by $M>n$ number of points which is considered to be 10 in the present investigation.

\section{Preparation of nano-sized blue pigments}

The procedure for the manufacture of cobalt aluminate spinel by autoignition in an industrial plant was simulated on the bench scale. The precursors were synthesized by mixing

Table 1 Proportions (mol\%) of metals in the blue pigment composition

\begin{tabular}{lrrr}
\hline Composition & \multicolumn{1}{c}{ Co } & \multicolumn{1}{c}{$\mathrm{Mg}$} & \multicolumn{1}{c}{$\mathrm{Zn}$} \\
\hline A & 100.00 & 0.00 & 0.00 \\
B & 50.00 & 50.00 & 0.00 \\
C & 50.00 & 0.00 & 50.00 \\
D & 75.00 & 25.00 & 0.00 \\
E & 50.00 & 25.00 & 25.00 \\
F & 75.00 & 0.00 & 25.00 \\
G & 83.34 & 8.33 & 8.33 \\
H & 58.34 & 33.33 & 8.33 \\
I & 58.34 & 8.33 & 33.33 \\
J & 66.67 & 16.66 & 16.66
\end{tabular}


stoichiometric contents of nitrates to achieve nano-sized blue spinels. The soles were prepared by completely dissolving the reagents in deionized water and the mixtures were mixed using a magnetic stirrer with simultaneous heating on a hot plate at $60{ }^{\circ} \mathrm{C}$. The glycine content was set above the stoichiometric amount of 4.5 moles per one mole of product, which was calculated according to propellant chemistry. Then, the selected fuel was slowly added drop-wise to the nitrate solutions with vigorous stirring to achieve homogenous soles. In order to study the effect of solution $\mathrm{pH}$ on autoignition, the obtained soles were divided into three parts. The $\mathrm{pH}$ of the solutions was adjusted at three levels of 2.5, 7.0 and 10.5 by mixing a few drops of nitric acid and ammonia. The solutions were heated on a hot plate and stirred until most of the water was evaporated. The violet gels were transferred to a porcelain crucible and heated in a muffle furnace at $500{ }^{\circ} \mathrm{C}$. Then, the obtained dark green voluminous fluffy products were ground to produce powders for calcination. Very fine blue powders were obtained after the resulting powders were calcined at $900{ }^{\circ} \mathrm{C}$ and $1000{ }^{\circ} \mathrm{C}$ for $1 \mathrm{~h}$. Based on propellant chemistry, ${ }^{15}$ the principle reaction occurring in the glycine-nitrate system can be represented as:

$$
\begin{aligned}
{[1} & -(x+y)] \mathrm{Co}\left(\mathrm{NO}_{3}\right)_{2} \cdot 6 \mathrm{H}_{2} \mathrm{O}+x \mathrm{Mg}\left(\mathrm{NO}_{3}\right)_{2} \cdot 6 \mathrm{H}_{2} \mathrm{O} \\
& +y \mathrm{Zn}\left(\mathrm{NO}_{3}\right)_{2} \cdot 6 \mathrm{H}_{2} \mathrm{O}+2 \mathrm{Al}\left(\mathrm{NO}_{3}\right)_{3} \cdot 9 \mathrm{H}_{2} \mathrm{O}+80 \mathrm{NH}_{4} \mathrm{OH} \\
& +45 \mathrm{H}_{2} \mathrm{NCH}_{2} \mathrm{COOH}+6.125 \mathrm{O}_{2} \rightarrow \mathrm{Co}_{1-(x+y)} \mathrm{Mg}_{x} \mathrm{Zn}_{y} \mathrm{Al}_{2} \mathrm{O}_{4} \\
& +9.0 \mathrm{CO}_{2}+55.25 \mathrm{H}_{2} \mathrm{O}+10.25 \mathrm{~N}_{2}
\end{aligned}
$$

\section{Characterizations of nano-sized blue pigments}

$L^{*} a^{*} b^{*}$ colour measurements were carried out on a UV-Vis spectrometer (Model Lambda 19, Perkin Elmer, USA) equipped with a deuterium lamp (Model SD 3651-06 TJ) in the visible wavelength region of 400-700 $\mathrm{nm}$. The crystalline phases of the powders were identified by X-ray diffraction (XRD, Model 6000, Shimadzu, Japan) at the rate of $1^{\circ} \mathrm{min}^{-1}$ using nickel filtered $\mathrm{Cu}-\mathrm{K} \alpha$ radiation in the $2 \theta$ range of $10-80^{\circ}$. The X-ray diffraction technique was used to identify the crystalline phases and also to calculate the average crystallite size according to the Scherrer equation: ${ }^{15}$

$$
D=\frac{0.9 \lambda}{\delta \cos \theta}
$$

where, $D$ is the crystallite size, $\lambda$ is the wavelength of X-ray $(\mathrm{Cu}-\mathrm{K} \alpha, 0.15418 \mathrm{~nm}), \delta$ is the width at the half height of the peak and $\theta$ is the diffraction angle. FT-IR spectra were recorded on a Fourier transform infrared spectrometer (Model Tensor 27, Bruker, Germany) in the range of $400-4000 \mathrm{~cm}^{-1}$. The specific surface areas of the powders were measured using a nitrogen adsorption instrument (Model Gemini 2375, Micromeritics, USA) at $77 \mathrm{~K}$ according to the Brunauer-Emmett-Teller (BET) technique. The pigments were degassed at $150{ }^{\circ} \mathrm{C}$ for $1 \mathrm{~h}$ before the measurements. The morphology of the blue pigments was observed by scanning electron microscopy (Model S4160; Hitachi Hightech, Japan). The sample for TEM observation was prepared by dispersing about $1 \mathrm{mg}$ powder in $10 \mathrm{~mL}$ ethanol with sonication and then a drop of the suspension was transferred onto a carbon-coated copper grid. After drying the sample, the TEM micrograph was obtained using a CM30 Philips electron microscope.

\section{Results}

\section{Colorant performance of synthesized powders}

Human colour memory is poor to identify colour differences. By considering this problem, the Commission International de l'Eclairage (CIE) defined a Cartesian colorimetric coordinate system, where reflected energy can be described by three coordinates. Therefore, a colour can be defined in the colour space by describing whiteness, redness and blueness which are shown by $L^{*}, a^{*}$ and $b^{*}$, respectively. The difference between two colours, $\Delta E$, is defined as the geometrical distance between two points:

$$
\Delta E=\sqrt{\left(a_{2}^{*}-a_{1}^{*}\right)^{2}+\left(b_{2}^{*}-b_{1}^{*}\right)^{2}+\left(L_{2}^{*}-L_{1}^{*}\right)^{2}}
$$

The variation in $\Delta E$ is represented in Fig. 2(a) as a function of metal proportions in comparison to the pure $\mathrm{CoAl}_{2} \mathrm{O}_{4}$, composition A. Obviously, the presence of magnesium and zinc influences the chromatic performance, where a sharp change in $\Delta E$ is observed due to the arrangement of $\mathrm{Mg}$ and $\mathrm{Zn}$ in the structure of the pigment crystal. By applying an appropriate combination of starting materials it is possible to control the difference between the colours. It is evident that a small difference is related to the pigments prepared with low contents of magnesium and zinc. In other words, if the same contents of these metals, $8.33 \mathrm{~mol} \%$, are added to composition the change in $\Delta E$ is negligible, which is composition $\mathrm{G}$. The largest differences correspond to the compositions prepared with a high content of $\mathrm{Mg}$ and $\mathrm{Zn}$. The chromatic performances of the powders produced with various contents of magnesium and zinc are considerably different. The presence of $\mathrm{Mg}$ and $\mathrm{Zn}$ in the crystal structure is the main reason for the whiteness of the pigment. A decrease in the proportions of these metals generally means a better colour development.

The analysis of $\Delta E$ is not a powerful method to gain knowledge about the replacement of cobalt by magnesium and zinc. The degree of blueness is mainly governed by the parameter $b^{*}$. Thus, a reliable analysis should be performed by comparing $b^{*}$ values to understand the effects of $\mathrm{Mg}$ and $\mathrm{Zn}$ on chromatic performance. The results presented in Fig. 2(b) show that the chromatic performance is considerably influenced by the presence of magnesium and zinc in the structure of the pigment. The maximum $b^{*}$ value can be obtained by employing $33.33 \mathrm{~mol} \% \mathrm{Zn}$ and $8.33 \mathrm{~mol} \% \mathrm{Mg}$. The possibility of replacing a percentage of $\mathrm{Mg}$ and $\mathrm{Zn}$ with $\mathrm{Co}$ in the pigment composition was confirmed to achieve a maximum $b^{*}$ value. The results of laboratory tests show that the replacement of $50.0 \mathrm{~mol} \%$ of cobalt with the same amount of magnesium and zinc causes the following remarkable effects: a considerable increase in $\Delta E$ and a sharp decrease in $b^{*}$ value, simultaneously. Moreover, magnesium causes a darkening of the colour. Pure magnesium and zinc aluminates crystallized in the isometric system usually represent white luster. Various amounts of other elements such 


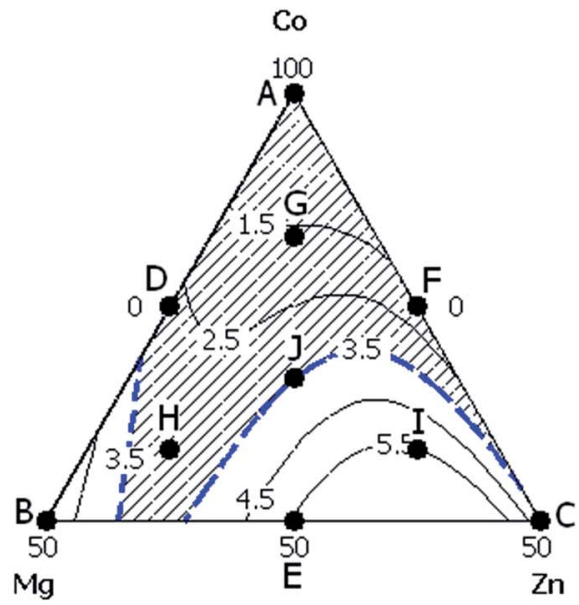

(a)

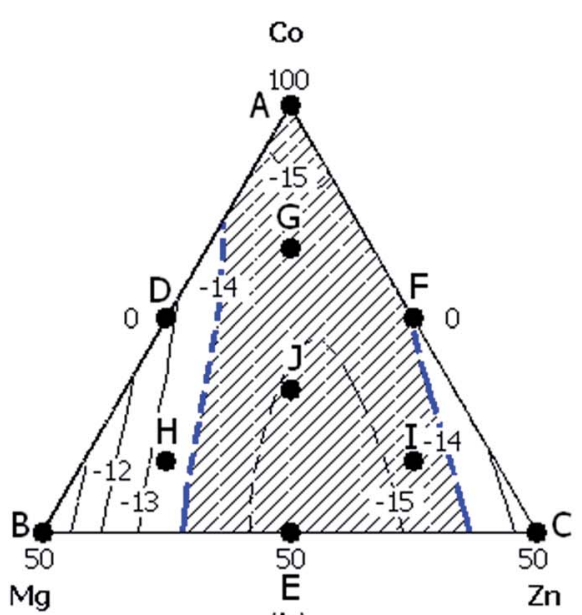

(b)

Fig. 2 Chromatic performance of blue pigments as a function of metal content (a) $\Delta E$ and (b) b*.

as cobalt impart different colors to the spinels, causing colored luster. The contour plot shows that the $b^{*}$ value varies nonlinearly with the content of metals and reaches the maximum value with addition of $58.33 \mathrm{~mol} \%$ cobalt. On the contrary, the magnesium content cannot be increased beyond $33.33 \mathrm{~mol} \%$ due to the significant change in the $b^{*}$ value. For this reason, the zinc content cannot be increased more than $33.33 \mathrm{~mol} \%$. Fig. 2(b) indicates that the $b^{*}$ value is more sensitive to changes in the amount of $\mathrm{Mg}$ and $\mathrm{Zn}$. For the composition prepared with $66.67 \mathrm{~mol} \%$ cobalt, the appropriate value of $b^{*}$ is observed compared to the other pigments. This composition results in a meaningful improvement in $b^{*}$ value.

\section{Crystal characteristics of synthesized powders}

Fig. 3 depicts the XRD patterns of the blue pigments synthesized with different combinations of divalent metals. The characteristic peaks of composition A are related to $\mathrm{CoAl}_{2} \mathrm{O}_{4}$ which were identified according to JCPDS no. 70-0753. The pattern shows the absence of a secondary phase. The main lines, which are characteristic of pure cobalt aluminate spinel, indicate that the precursors containing Co are better

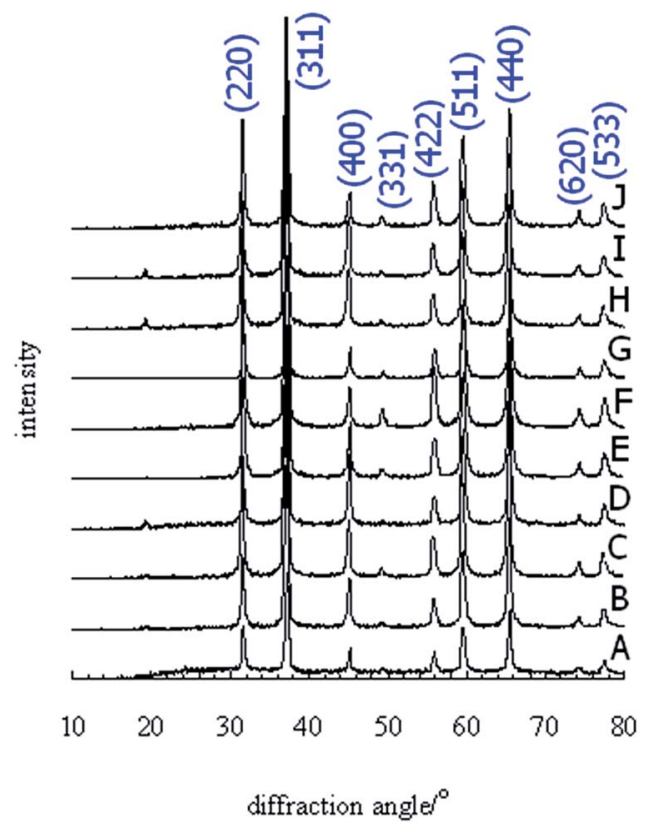

Fig. 3 XRD patterns of the pigments synthesized with different contents of $\mathrm{Co}, \mathrm{Mg}$ and $\mathrm{Zn}$ and calcined at $900{ }^{\circ} \mathrm{C}$.

recrystallized at $900{ }^{\circ} \mathrm{C}$. The diffraction peaks corresponding to the (220), (311), (400), (331), (422), (511), (440), (620) and (533) planes are identified and marked in Fig. 3 for all the studied compositions. The spinels seem to be pure and the patterns show the absence of any other crystalline phases. The mixtures of cobalt, magnesium, zinc and aluminium nitrates are more reactive to form a spinel structure by autoignition. The patterns of powders show the spinel peaks at the same diffraction angles, which proves their structural stability.

The growth of crystallites occurs at a high calcination temperature. The variation in crystallite size of the spinels, which were estimated using the Scherrer equation, is shown in Fig. 4 as a function of metal content. This factor increases with an increase in the amount of $\mathrm{Zn}$ and decreases with the

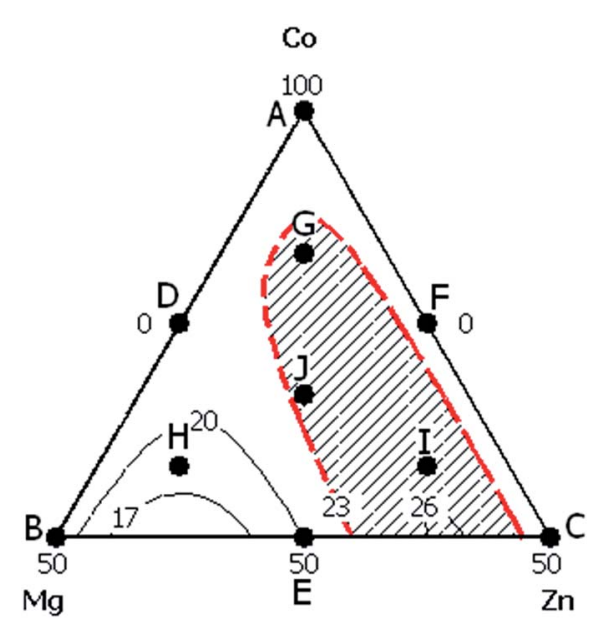

Fig. 4 Crystallite size of blue pigments as a function of metal contents. 
increment in $\mathrm{Mg}$ content. The powders containing a high level of $\mathrm{Mg}$ present smaller dimensions due to the smaller radius of $\mathrm{Mg}^{2+}$. The minimum crystallite size is related to the pigment containing $33.33 \mathrm{~mol} \%$ of magnesium. This figure indicates that the size grows with the cobalt and zinc contents and reaches the maximum value of $26 \mathrm{~nm}$ in the presence of 33.33 mol\% zinc. However, the pigment synthesized with a high content of cobalt presents the relatively medium dimension of $22 \mathrm{~nm}$. Overall, the variation in the crystallite size can be divided into two categories. When the $\mathrm{Mg}$ content is less than $16.67 \mathrm{~mol} \%$, the size is found to be $23-26 \mathrm{~nm}$, depending on the composition. When the precursor is prepared with a high content of magnesium, the crystallite size is between 19 and $23 \mathrm{~nm}$.

\section{Optimization of pigment composition}

The experimental values of colour difference, blueness and crystallite size significantly depend on the mixture ratio of divalent metals. The polynomial models can be adjusted to the experimental data related to colour difference, blueness and crystallite size as a function of metal proportions. The coefficients reported in Table 2 represent the correlations between the colour difference, blueness and crystallite size with the cobalt, magnesium and zinc proportions denoted by $z=1-(x+$ $y$ ), $x$ and $y$, respectively. The positive coefficient, which corresponds to the metal interactions, represents the effectiveness of the metals on the technical characteristics.

The statistical evaluations include the predicted correlation coefficient, $R^{2}$, and adjusted $R^{2}$ which shows the adjustment to a number of significant factors and their interactions. It should be note that the unnecessary terms are not considered in the models and good correlations are observable between the experimental and predicted values.

The maximum colour difference acceptable for the manufacture of blue pigment is 3.5 . Blueness of at least 14.0 is needed for the practical manufacture of blue pigments and the crystallite size should be a minimum of $21 \mathrm{~nm}$. The metal proportions corresponding to the optimum colour difference, blueness and crystallite size can be determined via contour plots. Fig. 5 illustrates the overlap of the technical factors in which the colour difference of $3.5, b^{*}$ of -14.0 and crystallite size of $21 \mathrm{~nm}$ are simultaneously obtainable by the employment of the same moles of magnesium and zinc, which is $16.66 \mathrm{~mol} \%$. According to the previous discussion, there is an appropriate range in which the technical factors are simultaneously improved by the mixing of divalent metals. The employment of $66.67 \mathrm{~mol} \%$ cobalt contributes to a decrease in colour difference and

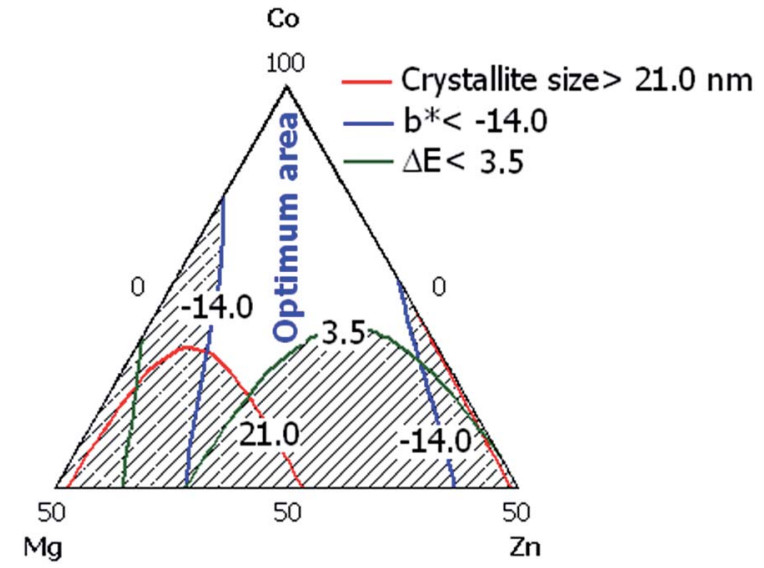

Fig. 5 Overlap of the colour difference, blueness and crystallite size for the pigments calcined $900^{\circ} \mathrm{C}$.

$b^{*}$ simultaneously. Based on the interaction of Fig. 2 and 4 , the common area was selected to minimize the crystallite size. Hence, the optimum combination of metals can be obtained from the interactions of the technical factors. An efficient increase in blueness cannot be achieved by changing the pigment composition; therefore an increase in calcination temperature is unavoidable.

\section{Effect of calcination temperature on technical factors}

The compositions denoted by A, F, G and J are located in the optimum area and indicate approximately similar values for the studied factors. Although, the composition I shows a higher $\Delta E$, the other technical characteristics are in the standard ranges defined for blueness and crystallite size in this investigation. Therefore, these compositions were selected to investigate the effects of calcination temperature and $\mathrm{pH}$. Table 3 reports the effect of calcination temperature on the chromatic performance. The precursors calcined at $1000{ }^{\circ} \mathrm{C}$ exhibit lower $b^{*}$ values, which indicates a blue hue. In the cobalt based pigments, $b^{*}$ gradually increases with an increase in the calcination temperature. However, it is worth noting that $b^{*}$ decreases to the minimum of -20.9 , for composition $\mathrm{J}$, and then slowly increases to -18.5 for composition G. In addition, the $\Delta E$ of the pigments also exhibit the same trend with an increase in temperature. This phenomenon can be ascribed to the changes in chromatic behaviour. The discrepancy between $b^{*}$ values mainly determines the quality of the pigment. The minimum $b^{*}$ is related to the pigment synthesized with 33.33 $\mathrm{mol} \% \mathrm{Zn}$, which indicates an increase in the degree of blueness.

Table 2 Coefficients of eqn (1) for the prediction of colour difference, blueness and crystallite size

\begin{tabular}{llrlllll}
\hline Factor & $z$ & $x$ & $y$ & $z x y$ & $z x^{2} y$ & $z x y^{2}$ & Predicted $R^{2}$ \\
\hline$\Delta E$ & $-3.2 \times 10^{-5}$ & 0.113 & 0.076 & 0.000 & $-3.6 \times 10^{-6}$ & $4.7 \times 10^{-6}$ & 0.982 \\
$b^{*}$ & 0.155 & -0.044 & -0.092 & $-1.3 \times 10^{-4}$ & 0.000 & 0.000 & 0.993 \\
$D$ & 0.231 & 0.196 & 0.199 & $2.6 \times 10^{-6}$ & 0.000 & 0.000 & 0.992
\end{tabular}


Table 3 Chromatic performance of selected pigments treated at two temperatures

\begin{tabular}{llllllll}
\hline & \multicolumn{2}{l}{$900{ }^{\circ} \mathrm{C}$} & \multicolumn{5}{l}{$1000{ }^{\circ} \mathrm{C}$} \\
\cline { 2 - 3 } \cline { 7 - 8 } Composition & $\Delta E$ & $b^{*}$ & $D(\mathrm{~nm})$ & & $\Delta E$ & $b^{*}$ & $D(\mathrm{~nm})$ \\
\hline $\mathrm{A}$ & 0.0 (base) & -14.2 & 22.2 & & 0.0 (base) & -20.2 & 27.1 \\
$\mathrm{~F}$ & 1.6 & -14.2 & 20.9 & & 0.6 & -20.6 & 26.7 \\
$\mathrm{G}$ & 1.3 & -15.3 & 23.6 & & 1.8 & -18.5 & 25.3 \\
$\mathrm{I}$ & 5.7 & -16.3 & 26.0 & 2.7 & -19.3 & 26.1 \\
$\mathrm{~J}$ & 3.5 & -15.5 & 23.0 & 2.4 & -20.9 & 26.9
\end{tabular}

When the $\Delta E$ values are less than 2.7 , the powders exhibit similar brightness.

\section{Effect of calcination temperature on technical factors}

The compositions denoted by A, F, G and J are located in optimum area and indicate the similar values for the studied factors, approximately. Although, the composition I shows higher $\Delta E$, the other technical characteristics are in standard ranges defined for blueness and crystallite size in this investigation. Therefore, these compositions were selected to investigate the effects of calcination temperature and $\mathrm{pH}$.

Table 3 reports the effect of calcination temperature on the chromatic performance. The precursors calcined at $1000{ }^{\circ} \mathrm{C}$ exhibit the lower $b^{*}$ values, indicating the blue hue. In the cobalt based pigments, the $b^{*}$ gradually increases with the rise in the calcination temperature. However, it is worth noting that the $b^{*}$ falls down to the minimum of -20.9 , composition $\mathrm{J}$, and then slowly increases to -18.5 , composition $\mathrm{G}$. In addition, $\Delta E$ of pigments also exhibit the same trend with rise in temperature. This phenomenon can be ascribed to changes in chromatic behaviour. The discrepancy between $b^{*}$ values mainly determines the quality of pigment. The minimum $b^{*}$ is related to the pigment synthesized by $33.33 \mathrm{~mol} \% \mathrm{Zn}$, indicating an increase in the degree of blue. The $\Delta E$ values are less than 2.7 and the powders exhibit a similar brightness. Therefore, the I and $\mathrm{G}$ compositions were selected as optimum pigments for further qualitative studies.

Fig. 6 shows XRD patterns of the powders calcined at $1000{ }^{\circ} \mathrm{C}$. The major peaks at $31,36,45,55,59,65,77$ and $78^{\circ}$ correspond to the $h k l$ reflections at 220, 311, 400, 422, 511, 440, 620 and 533, respectively. The patterns display reflections similar to that for $\mathrm{CoAl}_{2} \mathrm{O}_{4}$. The spinel phase is well recrystallized since the diffraction peaks of the powders become sharper and narrower with an increase in zinc content. Higher crystallinity is observed with a higher $\mathrm{Zn}$ doping, which well develops the crystalline structure. There are no extra peaks in the XRD patterns which indicate that the powders contain a single phase. The crystallite size of the powder is about $26 \mathrm{~nm}$ which is due to the fact that the higher calcination temperature results in a larger grain size.

\section{Effect of pH on technical factors}

The colour parameters of the powders prepared in acidic and alkali environments and calcined at $1000{ }^{\circ} \mathrm{C}$ are presented in

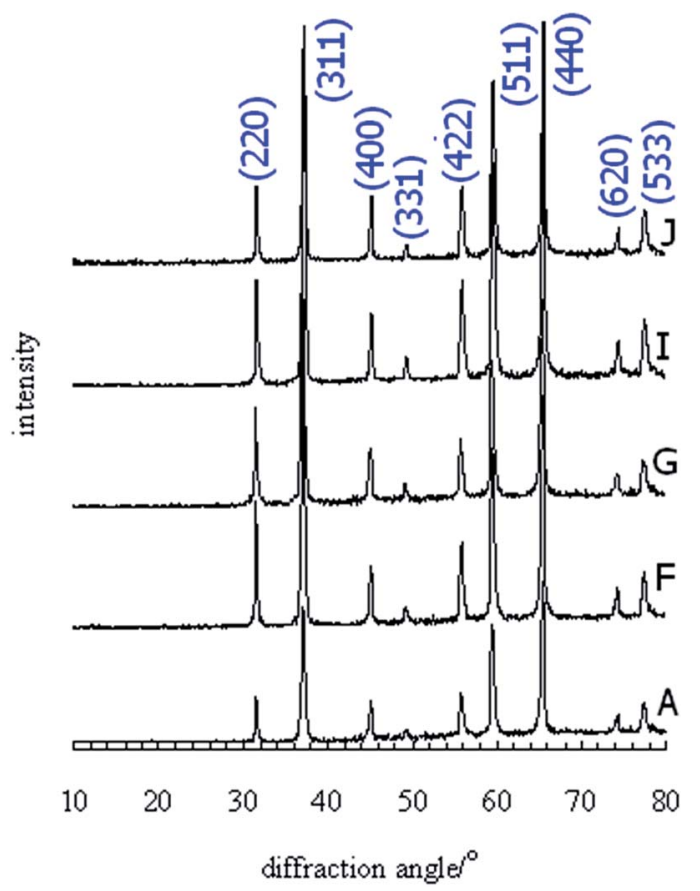

Fig. 6 XRD patterns of the pigments synthesized with different contents of $\mathrm{Co}, \mathrm{Mg}$ and $\mathrm{Zn}$ and calcined at $1000^{\circ} \mathrm{C}$.

Table 4. The $\mathrm{CoAl}_{2} \mathrm{O}_{4}$ nano-powder prepared in the absence of magnesium and zinc is considered as the reference powder. The presence of $\mathrm{Co}^{2+}$ arranged in the octahedral positions of the cubic close-packed lattice results in the coloration of the lattice. The chromatic performance is negligibly affected by the magnesium and zinc concentrations if the synthesis is carried out under neural and alkali conditions. The best blue colour is obtained when the synthesis is carried out in acidic conditions. Moreover, among the powders calcined at $1000{ }^{\circ} \mathrm{C}$, composition plays a strong role on chromatic performance due to the presence of magnesium. The colour difference increases when $\mathrm{pH}$ is below 7 due to the effective change in $b^{*}$.

Fig. 7 indicates the XRD patterns of the powders prepared in acidic and alkali conditions and calcined at $1000{ }^{\circ} \mathrm{C}$. The absence of other peaks means that the synthetic environment does not influence the purity of the powders. An improvement in the reflection intensity is seen in the powder synthesized under alkali conditions, which confirms the efficient recrystallization.

Table 4 Chromatic performance of selected pigments prepared under acidic and alkali conditions

\begin{tabular}{|c|c|c|c|c|c|c|}
\hline \multirow[b]{2}{*}{ Composition } & \multicolumn{3}{|l|}{2.5} & \multicolumn{3}{|c|}{10.5} \\
\hline & $\Delta E$ & $b^{*}$ & $D(\mathrm{~nm})$ & $\Delta E$ & $b^{*}$ & $D(\mathrm{~nm})$ \\
\hline $\mathrm{F}$ & 4.4 & -22.3 & 27.9 & 0.4 & -20.0 & 27.9 \\
\hline I & 3.4 & -18.8 & 26.5 & 3.9 & -18.4 & 23.5 \\
\hline $\mathrm{J}$ & 10.7 & -29.7 & 24.5 & 3.5 & -20.6 & 28.1 \\
\hline
\end{tabular}




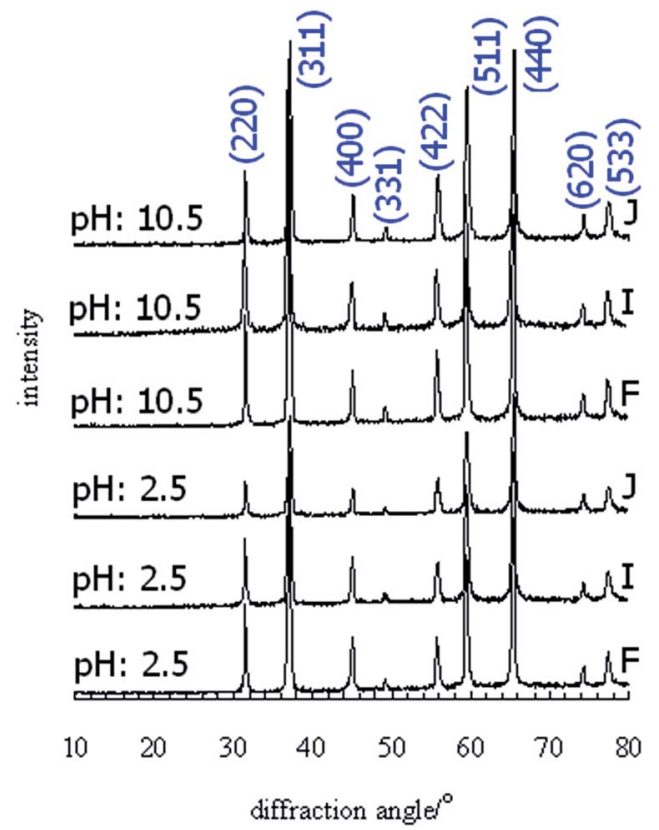

Fig. 7 XRD patterns of the pigments synthesized under acidic and alkali conditions with different contents of $\mathrm{Co}, \mathrm{Mg}$ and $\mathrm{Zn}$ and calcined at $1000^{\circ} \mathrm{C}$.

The effect of $\mathrm{pH}$ on crystallite size is also reported in Table 4. The thermal treatment of the products at $1000{ }^{\circ} \mathrm{C}$ results in the recrystallization of fine crystallites. Alteration of the solution conditions negligibly influences the crystallite size of the powders. The preparation of composition $\mathrm{J}$ in an acidic environment yielded a finely crystalline product with the average dimension of $24.5 \mathrm{~nm}$. As the $\mathrm{pH}$ increased, the crystallite size increased from 24.5 to $28.0 \mathrm{~nm}$. However, composition $\mathrm{J}$ is better recrystallized than the other cases. The crystallite size of the $\mathrm{F}$ and $\mathrm{I}$ compositions is not sensitive to $\mathrm{pH}$ and the grain growth in the powders obtained under alkali conditions occurs slowly. The crystallite size of the powders prepared at neutral $\mathrm{pH}$ is almost smaller than that for the powders synthesized at a $\mathrm{pH}$ of 10.5. The most influential parameter is temperature and $\mathrm{pH}$ only affects the crystallite size slightly.

\section{FTIR spectra of the pigments}

The FTIR spectra of the pigments synthesized under different conditions were recorded in the wavenumber range of 400-4000 $\mathrm{cm}^{-1}$, as illustrated in Fig. 8. The sharp bands at 500 and $660 \mathrm{~cm}^{-1}$ are characteristic of $\mathrm{CoAl}_{2} \mathrm{O}_{4}$. The spectrum related to composition A displays the characteristic bands due to normal $\mathrm{CoAl}_{2} \mathrm{O}_{4}$. The absorption band at $660 \mathrm{~cm}^{-1}$ is assigned to the Al$\mathrm{O}$ stretching vibration of $\mathrm{AlO}_{6}$ in the octahedral sites and the band at $500 \mathrm{~cm}^{-1}$ is attributed to the $\mathrm{Co}-\mathrm{O}$ stretching vibration of $\mathrm{CoO}_{4}$ in the tetrahedral positions. The same characteristic bands are observed in all the spectra. The metal-oxygen, aluminium-oxygen and metal-oxygen-aluminium stretching frequencies appeared in the range of $450-700 \mathrm{~cm}^{-1}$. The $\mathrm{MgO}_{4}$, $\mathrm{CoO}_{4}$ and $\mathrm{AlO}_{6}$ vibration bands appear at 500, 520 and 660 $\mathrm{cm}^{-1}$. The spectra exhibit a broad band at $3400-3450 \mathrm{~cm}^{-1}$

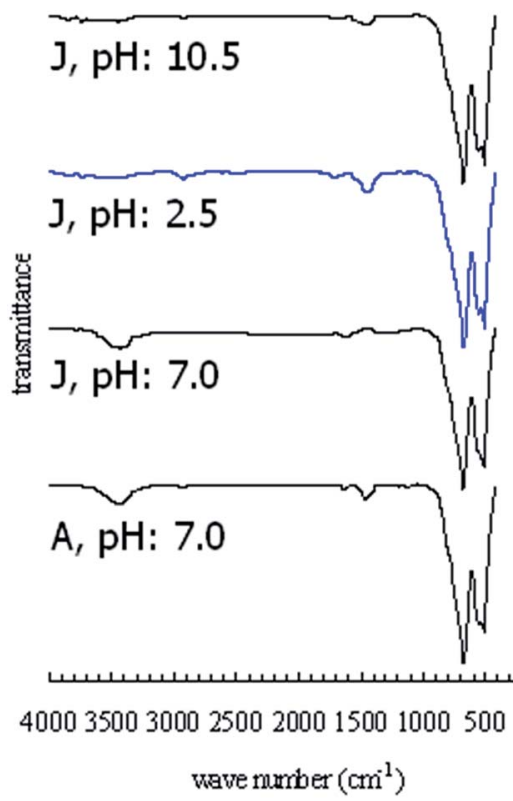

Fig. 8 FTIR spectra of the A and J compositions synthesized under acidic, neutral and alkali conditions.

corresponding to the $\mathrm{OH}$-stretching vibration. The starch bands related to $\mathrm{C}-\mathrm{O}$ and $\mathrm{C}=\mathrm{C}$ vibrations at $1410-1470 \mathrm{~cm}^{-1}$ and 1630-1640 $\mathrm{cm}^{-1}$, respectively, correspond to the presence of organic residuals. These results support the discussion presented for the XRD patterns.

\section{Morphology of pigment particles}

The SEM images of composition J are shown in Fig. 9. The calcination temperature has an important effect on the size and uniformity of the particles. An irregular morphology is observed for the nano-particles of $\mathrm{Co}_{0.67} \mathrm{Mg}_{0.16} \mathrm{Zn}_{0.16} \mathrm{Al}_{2} \mathrm{O}_{4}$ calcined at $900{ }^{\circ} \mathrm{C}$ and $1000{ }^{\circ} \mathrm{C}$, where significant structural differences were observed between the powders. The agglomeration and deposition of ultrafine particles occurred as white flakes in some positions. Cavities were formed between the particles in the pigment calcined at $900{ }^{\circ} \mathrm{C}$. An increase in calcination temperature led to the formation of closely packed clusters containing nano-particles.

Fig. 10 shows the SEM micrographs of the reference composition, $\mathrm{A}$, and composition $\mathrm{J}$ which was prepared in acidic and alkali environments. Fig. 10(a) indicates that the nanoparticles of $\mathrm{CoAl}_{2} \mathrm{O}_{4}$ are agglomerated. The pigment contains small particles which tend to agglomerate. The agglomerated clusters are dense, therefore they would not be separated easily by grinding and the cavities remained between the particles. Fig. 10(b) and (c) present the SEM images of J composition synthesized in acidic and alkali environments. There is an appreciable change in morphology when the synthesis was performed in acidic conditions. Large irregular clusters are not observed in this case and the grown particles consist of spherical grains. Small particles with variable shapes and sizes are observed along with micro-pores for the powder prepared in 


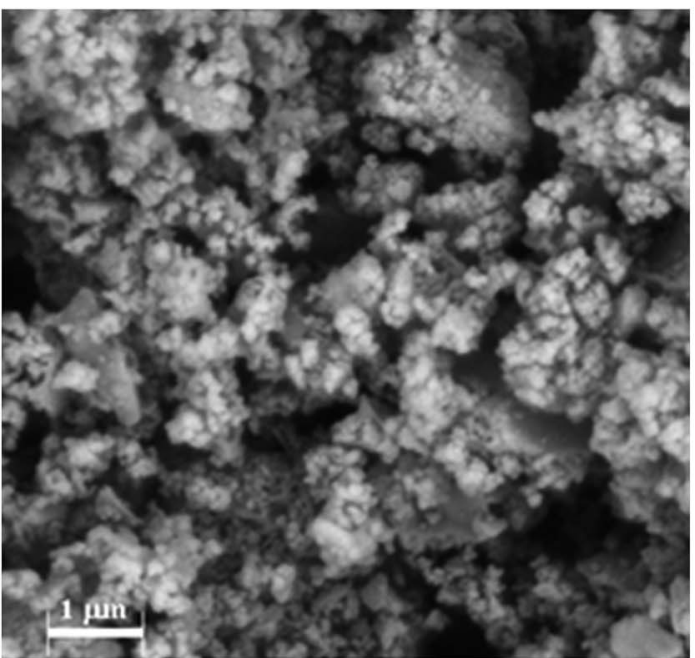

(a)

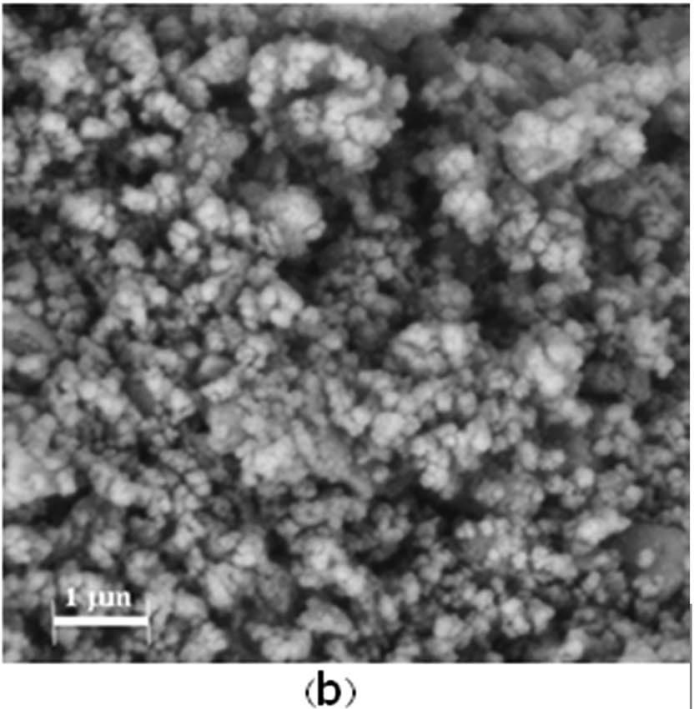

Fig. 9 SEM images of $\mathrm{J}$ composition prepared at $\mathrm{pH}$ of 7.0 and calcined at (a) $900{ }^{\circ} \mathrm{C}$ and (b), $1000^{\circ} \mathrm{C}$.

alkali conditions, thus the agglomeration seems to be controlled by $\mathrm{pH}$.

The TEM image of the optimum composition, J, which was calcined at $1000{ }^{\circ} \mathrm{C}$, is presented in Fig. 10(d). The powder exhibits particles with irregular shapes which are agglomerated due to calcination at a high temperature. The TEM image confirms the formation of nano-crystallites with cubic morphology. The powder consists of blocky particles with a diameter of $25-30 \mathrm{~nm}$ which is in good agreement with the value calculated from the XRD pattern. The order of magnitude obtained for the crystallite size by the Scherrer equation and TEM image is the same which proves the success of the applied methodology for the production of modified blue pigment.

The BET specific surface areas for the A and J compositions were close to 21.3 and $15.9 \mathrm{~m}^{2} \mathrm{~g}^{-1}$, respectively. The area of the $\mathrm{J}$ composition is less than that for $\mathrm{CoAl}_{2} \mathrm{O}_{4}$ which confirms the evolution of the crystallite size.

\section{Discussion}

Flame type autoignition was observed for the gels synthesized at $\mathrm{pH}$ of 2.5 whilst smouldering type combustion occurred for the gels prepared at pHs of 7.0 and 10.5. Flaming ignition is related to the gas phase reaction and endures for seconds or a maximum one minute, whereas the solid-gas reaction occurs in the smouldering type combustion and the gels undergo decomposition, which lasts almost 5 minutes. The ignition of the gel directly depends on dominant species of glycine. $\mathrm{NH}_{3}{ }^{+-}$ $\mathrm{CH}_{2} \mathrm{COOH}, \mathrm{NH}_{3}^{+} \mathrm{CH}_{2} \mathrm{COO}^{-}$and $\mathrm{NH}_{2} \mathrm{CH}_{2} \mathrm{COO}^{-}$are the dominant species formed in acidic, neutral and alkali conditions. ${ }^{26}$ Clearly the dissolution of hydroxides and protonation rate are promoted in the acidic environment. Therefore, interactions between $\mathrm{NH}_{3}{ }^{+} \mathrm{CH}_{2} \mathrm{COOH}$ and cations cannot be effectively formed and as a result the flame type ignition occurs in the gels prepared at a $\mathrm{pH}$ lower than 7.0. On the other hand, the -COOand $\mathrm{NH}_{2} \mathrm{CH}_{2} \mathrm{COO}^{-}$species cause strong interactions with cations which are beneficial for dispersion and facilitate the solid-gas reaction. In conclusion, a higher energy is needed for decomposition and smouldering ignition is observed when gel preparation is performed at a $\mathrm{pH}$ higher than 7.0. Thus, it is evident that different types of autoignition cause changes in chromatic performance.

The normal spinel characteristics were distinguished by the Raman spectrum of the blue powder and inverse spinel peaks were observed in the spectrum of green powder, as was previously reported. ${ }^{5}$ Therefore, the powder prepared by the combustion technique has favorable colorant behavior at $1000{ }^{\circ} \mathrm{C}$. It is established that the color of spinel pigments depends on the calcination temperature, divalent metal proportion and initial solution $\mathrm{pH}$. Independently, the ternary compositions calcined at $900{ }^{\circ} \mathrm{C}$ do not exhibit the appropriate chromatic properties, but that at $1000{ }^{\circ} \mathrm{C}$ show structural stability. Moreover, the blue color is quite stable at this temperature. The color characteristics of ternary compositions of $\mathrm{Co}_{0.75} \mathrm{Zn}_{0.25} \mathrm{Al}_{2} \mathrm{O}_{4}$ and $\mathrm{Co}_{0.67} \mathrm{Mg}_{0.16} \mathrm{Zn}_{0.16} \mathrm{Al}_{2} \mathrm{O}_{4}$ are approximately identical to the reference standard pigment. As the temperature increases, their bonds are better formed, which is in the agreement with previous literature. ${ }^{3,5,27}$ Owing to chromatic behaviour and calcination temperature, the mentioned compositions are suitable candidates for blue nano-pigment preparation in neutral environment. Although, the optimization of the synthetic condition yields nano-sized products, the specific surface area appears to be a function of cation radius in following order: $\mathrm{Mg}^{2+}<\mathrm{Zn}^{2+}<\mathrm{Co}^{2+}$, as reported previously. ${ }^{13}$

The $\mathrm{pH}$ of the solution plays an important role in coloration. The precursor containing Co is better recrystallized than that containing $\mathrm{Mg}$. Additionally, purity is slightly affected by $\mathrm{pH}$ during the formation of $\mathrm{CoAl}_{2} \mathrm{O}_{4}$. The purity of zinc aluminate powders is affected by $\mathrm{pH}$. However, the synthesis of spinel in acidic conditions results in $\mathrm{ZnAl}_{2} \mathrm{O}_{4}$. Independent of cation type, flame combustion occurs when the gel preparation is carried out in acidic conditions. The flame type autoignition produces sufficient energy for the diffusion of ions into the cubic structure to form a well-crystalline spinel. Although, the 


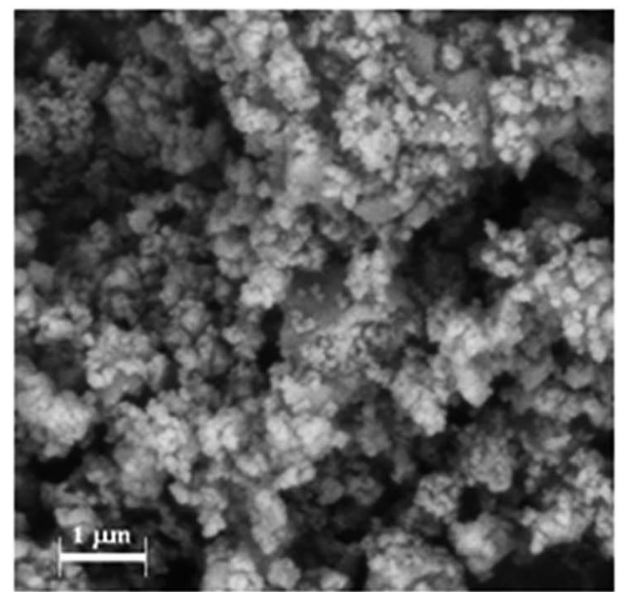

(a)

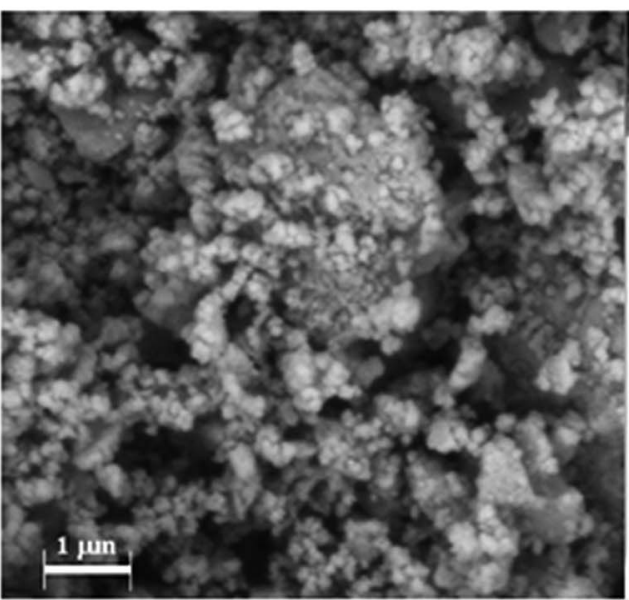

(C)

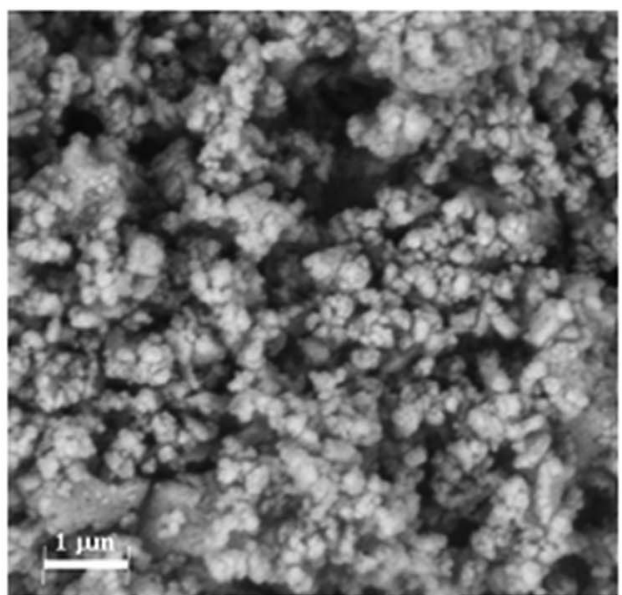

(b)

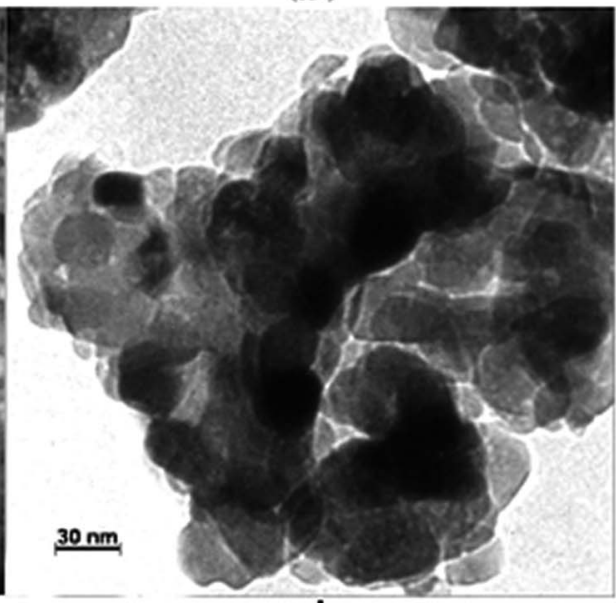

(d)

Fig. 10 SEM and TEM images of the powders calcined at $1000^{\circ} \mathrm{C}$. (a) A, synthesized at a pH of 7.0, (b) $\mathrm{J}$ prepared in acidic conditions, (c) $\mathrm{J}$ prepared in alkali environment and (d) optimum composition.

composition can influence the formation of spinel, $\mathrm{pH}$ plays a predominant role in the recrystallization of $\mathrm{Co}_{0.67} \mathrm{Mg}_{0.16}$ $\mathrm{Zn}_{0.16} \mathrm{Al}_{2} \mathrm{O}_{4}$ and as a result this spinel powder displays the best blue colour.

\section{Conclusions}

The chromatic performance of $\mathrm{Co}_{1-(x+y)} \mathrm{Mg}_{x} \mathrm{Zn}_{y} \mathrm{Al}_{2} \mathrm{O}_{4}$ was investigated to reduce the pollution risk and safely synthesize a nano-sized blue pigment via self-combustion. The interactions are highlighted as a function of divalent metal proportions in which the technical limits were considered in the synthesis of the pigment. The spinels with $\mathrm{Co}_{0.75} \mathrm{Zn}_{0.25} \mathrm{Al}_{2} \mathrm{O}_{4}$ and $\mathrm{Co}_{0.67} \mathrm{Mg}_{0.16} \mathrm{Zn}_{0.16} \mathrm{Al}_{2} \mathrm{O}_{4}$ formulas can be successfully employed for the manufacture of nano-sized blue pigment in a neutral environment. The chromatic performance substantially depends on the starting solution $\mathrm{pH}$ which plays a key role in the $b^{*}$ value of the final product. Pure spinel particles smaller than $30 \mathrm{~nm}$ can be synthesized under neutral conditions, which is of great practical importance. Although, the crystallite size slightly varies with $\mathrm{pH}$, the manufacture of spinel in an acidic environment improves the $b^{*}$ value considerably. The highly negative values of the $b^{*}$ coordinate $(\sim-30)$ obtained upon the simultaneous substitution of $\mathrm{Mg}^{2+}$ and $\mathrm{Zn}^{2+}$ in the $\mathrm{CoAl}_{2} \mathrm{O}_{4}$ spinel structure under acidic conditions indicates a darker blue pigment. In comparison to cobalt aluminate oxide, the modified composition can be economically applied for the production of nano-sized pigments via a clean and safe technique.

\section{References}

1 Sh. Salem, S. H. Jazayeri, F. Bondioli, A. Allahverdi and M. Shirvani, Thermochim. Acta, 2011, 521, 191.

2 P. M. T. Cavalcante, M. Dondi, G. Guarini, M. Raimondo and G. Baldi, Dyes Pigm., 2009, 80(2), 226.

3 Sh. Salem, S. H. Jazayeri, F. Bondioli, A. Allahverdi, M. Shirvani and A. M. Ferrari, Int. J. Appl. Ceram. Technol., 2012, 9(5), 968.

4 D. M. A. Melo, J. D. Cunha, J. D. G. Fernandes, M. I. Bernardi, M. A. F. Melo and A. E. Martinelli, J. Mater. Res. Bull., 2003, 38, 1559.

5 Sh. Salem, J. Ind. Eng. Chem., 2014, 20(3), 818. 
6 M. Yoneda, K. Gotoh, M. Nakanishi, T. Fujii and T. Nomura, Powder Technol., 2016, DOI: 10.1016/j.powtec.2016.06.021.

7 X. Xi, Z. Nie, L. Ma, L. Li, X. Xu and T. Zuo, Powder Technol., 2012, 226, 114.

8 W. Lv, Q. Qiu, F. Wang, S. Wei, B. Liu and Z. Luo, Ultrason. Sonochem., 2010, 17(5), 793.

9 A. Fernandez-Osorio, E. Pineda-Villanueva and J. ChavezFernandez, Mater. Res. Bull., 2012, 47(2), 445.

10 S. Kurajica, J. Popovic, E. Tkalcec, B. Grzeta and V. Mandic, Mater. Chem. Phys., 2012, 135(2-3), 587.

11 M. Lade, H. Mays, J. Schmidt, R. Willumeit and R. Schomacker, Colloids Surf., 2000, 163, 3.

12 J. Lu, K. Minami, S. Takami and T. Adschiri, Chem. Eng. Sci., 2013, 85, 50.

13 Sh. Salem, Ceram. Int., 2016, 42(1), 1140.

14 Sh. Salem, Mater. Lett., 2015, 139, 498.

15 Sh. Salem and S. Jafarzadeh-Ghoushchi, Chemom. Intell. Lab. Syst., 2016, 159, 80.

16 M. C. G. Merino, A. L. Estrella, M. E. Rodriguez, L. Acuna, M. S. Lassa, E. Gustavo, G. E. Lascalea and P. Vazquez, Procedia Mater. Sci., 2015, 8, 519.
17 L. F. Koroleva, Glass Ceram., 2004, 61(9-10), 299.

18 R. M. Khattab, H. E. H. Sadek and A. A. Gaber, Ceram. Int., 2017, 43(1), 234.

19 W. Bao, F. Ma, Y. Zhanga, X. Hao, Z. Deng, X. Zou and W. Gao, Powder Technol., 2016, 292, 7.

20 R. Ianos, R. Lazau and P. Barvinschi, Adv. Powder Technol., 2011, 22(3), 396.

21 J. S. Ahmed, S. A. Shama, M. M. Moustafa, H. A. Dessouki and A. A. Ali, Spectrochim. Acta, Part A, 2009, 74(3), 665.

22 L. K. C. de Souza, J. R. Zamian, G. N. da Rocha Filho, L. E. B. Soledade, I. M. G. dos Santos, A. G. Souza, T. Scheller, R. S. Angelica and C. E. F. da Costa, Dyes Pigm., 2009, 81, 187.

23 A. Sedghi, M. Alimohammadi and M. Chadorbaf zadeh, Ceram.-Silik., 2014, 58(2), 145.

24 D. Visinescu, C. Paraschiv, A. Ianculescu, B. Jurcad, B. Vasile and O. Carp, Dyes Pigm., 2010, 87(2), 125.

25 R. C. St. John, J. Qual. Technol., 1984, 2(16), 81.

26 T. Peng, X. Liu, K. Dai, J. Xiao and H. Song, Mater. Res. Bull., 2006, 41, 1638.

27 W. Li, J. Li and J. Guo, J. Eur. Ceram. Soc., 2003, 23, 2289. 